\title{
A Educação Especial em Maceió/Alagoas e a Implementaçấo da Política do Atendimento Educacional Especializado ${ }^{1}$ \\ Special Education and Implementation Policy of Educational Service SPECIALISTS IN MACEIÓ/ALAGOAS
}

\author{
David dos Santos CALHEIROS ${ }^{2}$ \\ Neiza de Lourdes Frederico FUMES ${ }^{3}$
}

\begin{abstract}
RESUMO: esta pesquisa busca recuperar aspectos da História da Educação Especial do município de Maceió/Al e analisar o atual processo de implantação da política do atendimento educacional especializado (AEE) na rede municipal desta cidade alagoana. Além disso, procuramos também descrever algumas das condiçóes geográficas, políticas, econômicas, sociais e educacionais da cidade de Maceió, em virtude de que estas características podem colaborar na compreensão de alguns dos resultados diagnosticados. Elegemos a análise documental como abordagem de pesquisa, a fim de diagnosticar a realidade estudada. Os resultados apontam que a Educação Especial, no município em questáo, é bastante recente e que, apesar disso, há alguns esforços para responder a atual política de oferta do AEE em unidades escolares da rede municipal de educaçáo. No entanto, diversas dificuldades foram encontradas, a saber: precária estrutura arquitetônica dos espaços escolares e ausência de profissionais habilitados. Estas dificuldades são consonantes com a realidade do município estudado que enfrenta sérios problemas de cunho econômico, político, social e educacional, os quais desfavorecem o desenvolvimento da Educaçáo como um todo e da Educação Especial em particular. Diante disso, urge a necessidade de políticas/açôes que promovam não somente a melhoria da formação profissional especializada para o AEE e das condiçôes de infraestruturas do espaço escolar, mas principalmente a valorização e o fortalecimento de um sistema municipal de educação que, por muito tempo, vem sofrendo com o descaso de más administraçóes públicas.
\end{abstract}

PALAVRAS-CHAVE: Educação Especial. Atendimento Educacional Especializado. Sala de Recursos Multifuncionais.

\begin{abstract}
This study seeks to recover aspects of the History of Special Education of the city of Maceió/AL and analyze the current process of policy implementation of specialized educational services (SES) in public schools of this city. In addition, we also describe some of the geographic, political, economic, social and educational conditions of the city of Maceió, because these characteristics may explain some of the results that were uncovered. We chose the documentary analysis approach as a way to diagnose the reality under investigation. The results indicate that Special Education in Maceió is fairly recent, and that despite this, attempts have been made to answer the current policies providing for SES schools of the municipal education system. Nevertheless, several difficulties were encountered, namely: precarious architectural structure of school buildings and the lack of qualified professionals. These difficulties are similar to the city's general reality, as a place that faces serious problems of economic, political, social and educational nature, which undercut the development of education as a whole and Special Education in particular. Therefore, there is urgent need for policies/actions to promote not only the improvement of specialized professional development for the SES and infrastructure conditions of school buildings, but mainly the enhancement and strengthening of the municipal system of education which, for many years has suffered the neglect of bad public administration.
\end{abstract}

KEYWORDS: Special Education. Specialized Educational Services. Multifunctional Resource Classroom.

\footnotetext{
${ }^{1}$ Esta pesquisa teve financiamento da Coordenação de Aperfeiçoamento de Pessoal de Nível Superior - CAPES e integra as açốes do Observatório Nacional de Educação Especial (ONEESP).

${ }^{2}$ Mestrando do Programa em Pós-Graduação em Educação Especial pela Universidade Federal de São Carlos - UFSCAR, São Carlos, SP, Brasil. david_calheiros@yahoo.com.

${ }^{3}$ Docente do Programa de Pós-Graduação em Educação Brasileira, Universidade Federal de Alagoas, Maceió, AL, Brasil. neizaf@ yahoo.com.
} 


\section{INTRODUÇÁo}

A partir da Constituição Federal de 1988 (BRASIL, 1988) e da Lei de Diretrizes e Bases da Educação Nacional de 1996 (BRASIL, 1996), a União, os estados e os municípios estão sendo convocados a reorganizar seus sistemas de ensino com base nos pressupostos do paradigma da educação inclusiva. Nesta perspectiva, o acesso ao ambiente educacional é apenas o passo inicial deste processo, sendo essencial também garantir a permanência, a aprendizagem e a qualidade dos serviços de ensino a todos os alunos, independentemente de suas características.

Em linhas gerais, no Brasil, a inclusão está dando seus primeiros passos e há ainda um extenso caminho a ser percorrido. Inúmeras pesquisas têm apontado falhas nos sistemas de ensino - inoperância dos órgãos diretivos, preconceitos, barreiras arquitetônicas e de comunicação, ausência e/ou precariedade de formação docente -, em seus diferentes níveis, que prejudicam significativamente a participação com sucesso de todos os alunos do cenário escolar (CAPELLINI; RODRIGUES, 2009; CHACON, 2004; MONTEIRO; MANZINI, 2008; SANTOS, 2011).

Mediante essa situação, entende-se que a inclusão educacional dependerá de transformaçóes macrossociais. Todavia, é imprescindível a proposição de políticas públicas específicas ao campo educacional que assegurem a participação efetiva de alunos com deficiência, transtornos globais do desenvolvimento e altas habilidades/superdotação nas escolas comuns, com oportunidades incondicionais de ampliação de seus conhecimentos e de prosseguimento em seus estudos.

Dentre as políticas públicas propostas para garantir a educação para todos, está a do Atendimento Educacional Especializado (AEE). O Decreto nº. 7.611, de 17 de novembro de 2011, define este atendimento como um sistema de apoio à escolarização de alunos com deficiência, transtornos globais do desenvolvimento e altas habilidades/superdotação. De uma forma mais específica, é o conjunto de atividades, recursos de acessibilidade e pedagógicos organizados contínua e institucionalmente, prestado de forma complementar ou suplementar à formação dos alunos no ensino regular (BRASIL, 2011b).

O AEE tem sido oferecido preferencialmente nas chamadas salas de recursos multifuncionais (SRM), com atuação situada na minimização/erradicação das insuficiências e barreiras que interferem prejudicialmente no aprendizado e na participação escolar de alunos com deficiência, transtornos globais do desenvolvimento e altas habilidades/superdotação ${ }^{4}$ (DIAS, 2010).

De acordo com Milanese (2012), as pesquisas sobre a efetivação do AEE são incipientes e poucas delas trazem resultados acerca dos serviços especializados que vêm sendo oferecidos nas salas de recursos multifuncionais. Isso se deve, em grande parte, à atualidade da política em todo o território brasileiro.

Assim, levando em consideração a necessidade de avaliar a implementação das SRM, urge o interesse em resgatar aspectos da História da Educação Especial do município de Maceió/AL e analisar o atual processo de implantação da política do atendimento educacional especializado (AEE) na rede municipal desta cidade alagoana. A pesquisa visa também descrever

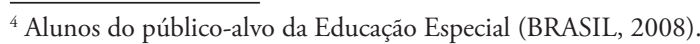


algumas das condições geográficas, políticas, econômicas, sociais e educacionais da cidade de Maceió, em virtude de que estas características podem colaborar na compreensão de alguns dos resultados diagnosticados.

\section{Aspectos metodológicos}

Nesta pesquisa de cunho qualitativo, optou-se por utilizar a análise documental, desenvolvida através de coletas de documentos escritos, a fim de diagnosticar a realidade estudada. Sobre análise de documentos, Flick (2009) menciona que o pesquisador deverá considerar quem os produziu e com quais objetivos foram idealizados. O autor ainda propóe evitar o foco apenas nos conteúdos dos documentos, mas ponderar seu contexto, sua utilização e sua função.

Nessa direção, foi analisada uma série de documentos ${ }^{5}$ que abordam a temática da Educação Especial e do AEE no município de Maceió/AL, conseguidos a partir de visitas in loco e/ou em sítios eletrônicos. Os locais visitados foram os seguintes: Secretaria Estadual de Educação de Alagoas (SEE/AL) e Secretaria Municipal de Educação (SEMED). No que se refere às consultas realizadas aos sítios eletrônicos, estas se limitaram ao do Instituto Brasileiro de Geografia e Estatística (IBGE), do Instituto Nacional de Estudos e Pesquisas Educacionais Anísio Teixeira, do Ministério da Educação, da SEE/AL e da SEMED/Maceió.

A partir do mapeamento foram recolhidos os documentos necessários à caracterização da Educação Especial de Maceió/AL. Cabe destacar que foram coletados apenas os dados com publicação posterior ao ano de $1958^{6}$, data que marca o início do serviço de Educação Especial no município de Maceió (ALAGOAS, 2005). Os documentos utilizados neste estudo apresentavam-se na forma impressa e/ou em arquivos eletrônicos.

Uma leitura flutuante dos materiais recolhidos permitiu que se fizesse o reconhecimento dos temas relevantes, originando as seguintes categorias: 1. Condiçôes geográficas, políticas, econômicas e sociais da cidade de Maceió/AL; 2. Dados sobre sistema de ensino do município; 3. Notas sobre a história da Educação Especial de Maceió e 4. O atendimento educacional especializado em salas de recursos multifuncionais.

A coleta de dados da pesquisa teve início após a aprovação do projeto pelo Comitê de Ética em Pesquisa com Seres Humanos da Universidade Federal de Alagoas (CEP/UFAL), sob o parecer no 009637/2011-73. Este projeto integra o Observatório Nacional de Educação Especial (ONEESP) ${ }^{7}$.

\footnotetext{
${ }^{5}$ Os documentos analisados foram: artigos, dissertaçôes, decretos, portarias, planos estaduais e municipais, documentos obtidos na Secretaria Estadual e Municipal de Educaçáo.

${ }^{6}$ Contudo, parece importante que outras pesquisas, de caráter histórico, sejam realizadas para ampliar a compreensão deste processo, sobretudo no período anterior a 1958.

${ }^{7}$ Rede formada por pesquisadores, provenientes de diversos estados e instituiçôes de ensino superior de todo o Brasil, que desenvolvem um estudo em rede nacional sobre as Salas de Recursos Multifuncionais nas escolas comuns, com coordenação nacional da Profa. Dra . Enicéia Gonçalves Mendes.
} 


\section{Resultados E Discussão}

Os resultados obtidos na pesquisa documental serão apresentados e discutidos obedecendo à sequência de categorias anteriormente referidas.

\subsection{CONDIÇÓEes GEOGRÁFICAS, POLÍTICAS, ECONÔMICAS E SOCIAIS DA CIDADE DE MACEIÓ/AL}

Alagoas é um dos 27 estados do Brasil, localizado na região nordeste do país, entre os estados da Bahia e de Pernambuco. Atualmente, possui 102 municípios, que correspondem a uma área territorial de $27.779,343 \mathrm{~km}^{2}$, banhada pelo Rio São Francisco e rica em um ecossistema natural, a saber: Mata Atlântica; Dunas; Restinga; Recifal e Várzea (BRASIL, 2010c). O estado recebe grande visitação de turistas de todo o país e do mundo durante o ano, sobretudo por conta de suas praias (ALAGOAS, 2011). Estima-se que o território alagoano seja povoado por 3.120.922 habitantes, dos quais 48,45\% são homens e 51,55\% são mulheres (ALAGOAS, 2011). De acordo com dados do IBGE, grande parte da população alagoana reside em áreas urbanas $-73,64 \%$-, enquanto uma parcela consideravelmente menor habita nas áreas rurais do estado - 26,36\%.

Em termos econômicos, Alagoas tem como principais fontes de renda e de sobrevivência da população as atividades relacionadas ao comércio, turismo, agricultura e indústria. De acordo com a Secretaria de Estado do Planejamento e do Desenvolvimento Econômico (ALAGOAS, 2012), esses segmentos contribuíram para o aumento do Produto Interno Bruto do estado, que no ano de 2009 foi de 21.234.950,71 bilhóes, correspondente ao décimo lugar no ranking brasileiro. No entanto, tal crescimento econômico não tem beneficiado toda a população: sem grandes oportunidades de emprego, consequentemente, não há geração de renda para todos os habitantes. Isso caracteriza o estado como um dos piores do país no que diz respeito à distribuição de renda (CALDAS, 2010; LINS, 2010).

Ainda considerando o ano de 2009, os dados do PIB demonstraram que Maceió foi a cidade responsável por $48,34 \%$ da geração de riquezas produzidas no estado, com um valor de 10,264 bilhões de reais (ALAGOAS, 2012). Esta grande convergência da economia de Alagoas para a cidade de Maceió se dá devido ao fato de este município ser a capital do estado e concentrar as principais oportunidades de geração de renda. Em termos econômicos, Maceió se destaca pelas atividades de cunho industrial, comercial, educacional, de saúde e turismo. Contudo, esta concentração populacional trouxe consigo uma série de problemas sociais, como a favelização (LINS, 2010), o crescimento do mercado informal e as atividades irregulares - atividades autônomas de sobrevivência, tais como: catador de material reciclável, vendedor ambulante, pedinte, limpador de para-brisas, guardador de carro, entre outras (CARVALHO, 2008).

De acordo com Suica (2012), outro desdobramento do crescimento econômico e da consequente má distribuição de renda na cidade de Maceió/AL é o alto índice de violência. Para se ter uma ideia mais precisa deste caso, recorre-se às pesquisas de Waiselfisz (2012), em que aponta a capital alagoana, em 2010, com a concentração de praticamente a metade dos homicídios do estado de Alagoas, sendo 109,9 homicídios em 100 mil habitantes. Este dado ainda revela que Maceió é a capital brasileira com maior taxa de homicídios, ocupando a $1^{a}$ posição no ranking nacional. A violência local de Maceió está presente em toda a dimensão 
territorial da cidade, ainda que se concentre nas regiôes periféricas, sendo imprescindível a criação de políticas públicas governamentais para combater esta fragilidade municipal.

Sobre os aspectos territoriais e populacionais, é relevante mencionar que Maceió tem uma área de 503, $072 \mathrm{~km}^{2}$, distribuídos em 50 bairros, com uma população de 932.748 habitantes, equivalente a aproximadamente $30 \%$ da população alagoana (BRASIL, 2010b). De acordo com o Censo Demográfico de 2010 (BRASIL, 2010b), 46,8\% dos habitantes de Maceió são homens e os outros 53,2\% são mulheres, sendo que 99,9\% residem em área urbana, enquanto apenas $0,1 \%$ habita em áreas rurais.

A respeito das condiçóes das habitaçóes em áreas urbanas e rurais de Maceió, Silva (2011) menciona que os condicionantes para a ocupação são os próprios limites físicos de seu sítio natural, compreendido pelo oceano Atlântico, Lagoa Mundaú e por aglomerado de grotas e encostas. De acordo com Melo e Lins (2010), as grotas, as encostas da cidade e as margens da Lagoa Mundaú são os locais frequentemente utilizados para os assentamentos de grande parte da populaçáo menos favorecida economicamente. As autoras prosseguem afirmando que dez dos cinquenta bairros de Maceió localizam-se às margens da Lagoa, nas quais moradias impróprias - como barracos de madeira e de papelão - são facilmente encontradas, o que gera uma grande preocupação quanto à integridade humana dos moradores.

A condição de vulnerabilidade na cidade de Maceió/AL não engloba apenas o âmbito econômico e habitacional, mas também diz respeito à educação. De acordo com os Indicadores Sociais Municipais, em Maceió, no ano de 2010, os percentuais de crianças de 10 anos de idade que não sabiam ler ou escrever eram bastante preocupantes (BRASIL, 2011a). Dentre as capitais brasileiras, Maceió apresentava a pior situação: 11,6\% dos escolares nessa faixa etária eram analfabetos.

\subsection{Dados SOBRE SISTEMA DE ENSINO dO MUNICÍPIO DE MACEIÓ}

A rede municipal de ensino de Maceió/AL é formada por sistemas de ensino público (federal, estadual e municipal) e privado (inclui-se aqui também a filantropia), ofertando serviços em nível de Educação Básica e Educação Superior. No que se refere à Educação Básica de Maceió, são atendidos cerca de 226.504 alunos devidamente matriculados (BRASIL, 2012a). Destas matrículas, 83.669 pertencem ao sistema privado de ensino, 1.978 à rede federal, 83.158 ao sistema estadual e 57.699 à rede municipal.

No que se refere às 57.699 matrículas da rede municipal de educação de Maceió, constatou-se, através da Secretaria Municipal competente, que a capital alagoana possui em funcionamento 131 estabelecimentos de ensino, subdivididos em oito regióes administrativas, responsáveis por atender educacionalmente os alunos matriculados. A participação dessas matrículas por nível educacional registra os seguintes índices: 7.210 matrículas na educação infantil; 43.333 no ensino fundamental; e 7.156 no ensino de jovens e adultos (BRASIL, 2012a).

No município maceioense, além de escolas de Educação Básica, existem também Instituiçốes de Ensino Superior (IES). Consulta ao Sistema e-MEC do Ministério da Educação apontou que, em 2012, havia 38 IES cadastradas, sendo 20 na modalidade presencial e 18 
no sistema de Educação a Distância (EAD) (BRASIL, 2012b) - duas Universidades Públicas (Universidade Federal de Alagoas e Universidade Estadual de Ciências da Saúde de Alagoas), um Centro Universitário (particular) e 35 faculdades (particulares). Este quadro se mantém inalterado em 2013.

Cabe ainda destacar que, tanto na Educação Básica, como na Educação Superior, a presença do público-alvo da Educação Especial se fazia presente no sistema de ensino de Maceió, ainda que a maior concentração estivesse na Educação Básica. De um modo particular, na Educação Básica eram 3.680 matrículas, destas 265 encontravam-se na educação infantil, 2.859 no ensino fundamental, 81 no ensino médio, 05 na educação profissional e 470 na educação de jovens e adultos (BRASIL, 2012a).

No que se remete às matrículas exclusivas na rede municipal de educação de Maceió, os dados do Censo Escolar 2012 atestavam que 1.795 alunos da Educação Especial estavam devidamente matriculados nos diferentes níveis de ensino - educação infantil, 109 matrículas; ensino fundamental, 1.573 matrículas; educação de jovens e adultos, 113 matrículas (BRASIL, 2012a).

Em relação ao índice de matrículas no Ensino Superior, em instituições localizadas em Maceió, verificou-se que, em 2010, havia 200 alunos da Educação Especial com registro acadêmico em um curso de graduação (BRASIL, 2010d).

Considerando o crescente número de matrículas nos diferentes níveis de ensino (BRASIL, 2011d; BRASIL, 2012a), a educação parece estar se tornando um bem mais acessível à sociedade, principalmente para grupos que estiveram ao longo do tempo excluídos da escola. No entanto, ainda é necessário percorrer um longo caminho para garantir a qualidade da educação e serviços de apoio que eliminem as barreiras de aprendizagem, como será visto posteriormente.

Neste sentido, Lykouropoulos (2007), analisando os dados oficiais, verificou que, apesar de o número de matrículas na Educação Especial no sistema municipal de ensino de Maceió ter crescido, principalmente de 1999 a 2003, houve, neste mesmo período, o encerramento de serviços da Educação Especial, como as salas de recursos ${ }^{8}$, e a drástica redução de professores especialistas em Educação Especial. Isto aconteceu anteriormente ao início das ações do Programa de Implantação de Salas de Recursos Multifuncionais, que ocorreu em 2005.

Ainda em relação à qualidade desse serviço educacional oferecido em Alagoas e em Maceió, os resultados apontados pelo Índice de Desenvolvimento da Educação Básica (IDEB) não são satisfatórios; ao contrário, são extremamente preocupantes. Para se ter ideia, entre 2009 e 2011, Alagoas foi avaliado com o menor IDEB de todo o país nos ciclos inicial e final do Ensino Fundamental (3,8 e 2,9 pontos, respectivamente) e obteve pontuação de 2,9 no Ensino Médio, superior apenas ao estado do Pará. No mesmo período, Maceió apresentou 3,8 na avaliação do IDEB, o que indica que a cidade, em termos educacionais, não conseguiu evoluir de acordo com as metas projetadas. De acordo com o Instituto Nacional de Estudos

\footnotetext{
${ }^{8}$ Entende-se como sala de recursos "o local com equipamentos, materiais e recursos pedagógicos específicos à natureza das necessidades especiais do alunado, onde se oferece a complementação do atendimento educacional realizado em classes do ensino comum" (BRASIL, 1994, p. 21).
} 
e Pesquisas Educacionais Anísio Teixeira, em 2011 esperava-se que o sistema municipal de ensino de Maceió chegasse a 4,0, o que não aconteceu (BRASIL, 2012c).

Apesar de todas as controvérsias inerentes a esta avaliação, não se pode deixar de considerar que ela aponta para as fragilidades do sistema de ensino e reclama açóes urgentes que modifiquem os baixos índices educacionais e garantam melhorias na qualidade de ensino, de forma a oportunizar condições concretas de participação e de desenvolvimento acadêmico de todos os alunos.

\subsubsection{Notas sobre a história da EducaÇáo Especial de Maceió}

As pessoas com deficiência, maciçamente e por longos períodos, estiveram alijadas do direito à educaçáo e, quando este direito começou a ser efetivado, isto ocorreu de forma segregada, em instituiçóes especializadas. No Brasil, apenas nas últimas décadas do século XX e início do século XXI o acesso à educação foi ampliado. Tal ampliação, porém, não é suficiente para tornar a educação um direito garantido a todos os brasileiros, como revelam os elevados índices de desescolarização entre as pessoas com deficiências consideradas mais abrangentes e a concentração de matrículas de pessoas com deficiência em escolas de grandes centros urbanos, localizados principalmente nas regióes Sul e Sudeste. Em linhas gerais, a trajetória e os modelos educativos para a pessoa com deficiência no estado de Alagoas e na sua capital não se configuraram de forma diferente, ainda que apresentem peculiaridades, como será mostrado a seguir. Diante disso, é interessante destacar algumas das características fundamentais que marcaram esse processo histórico da Educação Especial ao longo dos anos. De maneira semelhante ao que aconteceu em outros estados, em Alagoas, as principais açóes para o atendimento educativo da pessoa com deficiência tiveram início em Maceió, a capital do estado, e, portanto, palco das principais açóes políticas. As primeiras açóes relacionadas à implantação da Educação Especial na rede de ensino oficial aconteceram na segunda metade do século XX. Em 1958, foi ofertada a escolarização para pessoas com deficiência intelectual (ALAGOAS, 2005). Essa informação, de certa forma, ajuda a entender que a Educação Especial em Maceió tem sua gênese muito tardiamente, se comparada com outras capitais brasileiras, como, por exemplo, da cidade do Rio de Janeiro'. A proposição e a adoção tardias de políticas públicas na Educação Especial de Maceió são características que permanecem até os dias atuais.

Ademais, o serviço educacional voltado às pessoas com deficiência na cidade de Maceió, por muitos anos, foi oferecido com incentivo e apoio unicamente do governo estadual de Alagoas, já que, até então, a modalidade de ensino em Educação Especial não fazia parte da rede municipal de educação da capital alagoana. Enquanto a cidade de Maceió não sistematizava suas açóes educativas para o acolhimento das pessoas com deficiências, o Estado tinha que procurar garantir esse serviço educacional. Neste sentido, em 1973, o governo estadual criou, na Secretaria de Estadual de Educação, o Departamento de Educação Especializada, com o intuito de ampliar a oferta de serviços em todo o território alagoano (ALAGOAS, 2005).

Após a implantação do Departamento de Educação Especializada, percebeu-se que, de fato, houve um maior amparo das instâncias governamentais para o atendimento educacional das pessoas com deficiência. Sob sua égide, foram construídas, em Maceió, uma

${ }^{9}$ De acordo com Jannuzzi (2004), a então capital brasileira iniciou o serviço de Educação Especial ainda no período imperial. 
escola especializada em pessoas cegas (Escola Estadual Ciro Accioly - 1976) e um centro especializado principalmente na educação de alunos com deficiência intelectual e transtornos globais do desenvolvimento (Centro de Educação Especial Profa Wandete Gomes de Castro 1994) (ALAGOAS, 2005). Cabe destacar que a ampliação dos serviços educacionais especiais não aconteceu exclusivamente em Maceió, porém em outras cidades do interior do estado teve um ritmo mais lento e por muito tempo esteve restrita apenas às principais cidades do Estado.

O poder executivo do município de Maceió passou a ter um papel mais ativo e uma ação mais propositiva apenas nos anos 1980, com a criação, em 1985, do Departamento de Educação Especial da Secretaria Municipal de Educação (DEE/SEMED). O objetivo inicial do órgão foi realizar a caracterização dos estudantes a serem atendidos pela modalidade da Educação Especial e fazer o diagnóstico das condiçôes de infraestrutura do sistema de ensino. Esta análise visava à implantação de classes especiais para o atendimento de alunos com deficiência. Nesta direção, entre 1990 a 1994, foram construídas 13 classes especiais ${ }^{10}$ em diferentes instituiçôes de ensino (MACEIÓ, 2012c).

De acordo com Lykouropoulos (2007), estas classes especiais estavam localizadas em escolas regulares da rede municipal de ensino de Maceió e funcionavam na perspectiva do paradigma da integração. Todavia, embora este modelo de integração oportunizasse a entrada de pessoas com deficiência no ensino comum, a sua participação educacional ainda era precária, uma vez que estavam longe das condiçóes adequadas para o seu desenvolvimento acadêmico e social. De acordo com Mendes (2010), as classes especiais serviam como ambientes de segregação de boa parte dos alunos com necessidades educacionais especiais.

Até 1994, a rede municipal de ensino de Maceió concentrava suas atuaçóes em torno de uma política de integração que, em muitas das vezes, contribuía apenas para o processo de exclusão do aluno com deficiência.

Em 1996, a SEMED começou a mudar as orientaçóes para a educação do aluno com deficiência e passou a caminhar em direção ao movimento internacional e nacional em torno da inclusão educacional, que defende a participação de todos em uma única escola, independentemente das diferenças. Para tanto, foram criadas pela SEMED, através do DEE, duas Jornadas de Educação Especial, sendo a primeira' ${ }^{11}$ realizada em 1996 e a segunda ${ }^{12}$, em 1999. Ambas objetivaram discutir propostas para a construção de uma educação inclusiva no município de Maceió (LYKOUROPOULOS, 2007).

Em linhas gerais, entre 1999 e 2001, a discussão sobre a educação inclusiva ${ }^{13}$ paulatinamente se estendeu a toda a rede municipal de educação de Maceió, ao passo que também se deu início o processo de transformação das 18 classes especiais, distribuídas em 12 escolas municipais, em salas de recursos que funcionariam como apoio especializado às pessoas

\footnotetext{
${ }^{10}$ Estas classes eram estruturadas em escolas regulares e tinham o intuito de "se constituir em um ambiente próprio e adequado ao processo de ensino/aprendizagem do alunado da educação especial”. Professores utilizavam "métodos, técnicas e recursos pedagógicos especializados e, quando necessário, equipamentos e materiais didáticos específicos” (BRASIL, 1994, p. 19).

${ }^{11}$ A I Jornada de Educação Especial teve um público aproximado de 200 participantes, constituído por pais, professores e especialistas (MACEIÓ, 2012a).

${ }^{12}$ Da II Jornada de Educaçáo Especial, participaram representantes do Departamento de Gerenciamento Escolar da SEMED e do Sindicato dos Trabalhadores de Educação de Alagoas (MACEIÓ, 2012a).

${ }^{13}$ Esse trabalho foi conduzido pela equipe técnica do DEE (BARROS, 2011).
} 
com deficiência, transtornos globais do desenvolvimento e altas habilidades/superdotação (MACEIÓ, 2012a).

De acordo com Barros (2011), esse período focou na sensibilização/convencimento da comunidade escolar, pois existia certa resistência dos profissionais da rede de ensino municipal em relação à inclusão dos alunos com deficiência, que até então pouco chegavam à escola regular. Ao mesmo tempo, a autora ainda informa ser grande a insegurança dos professores que lecionavam em turmas de ensino regular quanto à sua habilidade para receber alunos com deficiência em suas salas de aula. Vale lembrar que o modelo educativo inclusivo rechaça a homogeneização do ensino, ao tempo em que prioriza a democratização e a universalização do ensino para todos.

Para minimizar a inquietação gerada entre os professores da rede municipal de educação de Maceió diante da inclusão e auxiliá-los nesse novo tipo de atuação, o DEE/SEMED propôs ações no âmbito da formação continuada ${ }^{14}$. Inicialmente, tais açôes destinavam-se apenas aos professores das antigas classes especiais e só posteriormente foram estendidas para os professores das salas comuns. Contudo, embora estes professores de sala de aula comum não estivessem sendo qualificados formalmente, recebiam apoio da equipe técnica do DEE/SEMED, através de um serviço de itinerância ${ }^{15}$, cujo objetivo era orientar e acompanhar os professores e alunos com necessidades educacionais especiais no processo educativo (BARROS, 2011).

Somente a partir de 2004 é que se percebem iniciativas pontuais de cursos de formação continuada na perspectiva da educação inclusiva, direcionadas aos professores de classes comuns que possuíam alunos com deficiência, promovidas pelo próprio DEE/SEMED (BARROS, 2011). Em 2005, de acordo com a mesma autora, estas formaçóes oferecidas pela SEMED passaram a receber financiamento do Fundo Nacional de Desenvolvimento da Educação e foram ampliadas para toda a rede municipal de ensino. Foram atendidos professores do ensino regular, de todos os segmentos, níveis e setores da Educação do sistema municipal.

De 2005 até os dias atuais, Maceió passou a seguir a tendência nacional estabelecida pela Política Nacional de Educação Especial na perspectiva da Educação Inclusiva (BRASIL, 2008) e focou suas açóes na oferta de AEE em Salas de Recursos Multifuncionais (SRM). Com isso, as salas de recursos passaram a ser substituídas pelas SRM, processo que será discutido com mais profundidade no subtópico a seguir.

Em suma, as notas sobre o histórico da Educação Especial em Maceió, discutidas ao longo desta categoria, permitem afirmar que o atendimento educacional à pessoa do públicoalvo da Educação Especial é proveniente de um movimento hodierno na rede municipal de ensino e que, apesar da sua atualidade, segue as discussóes que aconteciam/acontecem em contexto nacional e internacional.

\footnotetext{
${ }^{14}$ Grande parte das formaçōes contínuas realizadas teve participação conjunta dos governos municipal e federal. Dentre elas, podem-se citar: Formaçăo de Gestores e Educadores; Programa Educaçáo Inclusiva: direito à diversidade; Educar na Diversidade; Atendimento Educacional Especializado.

${ }^{15}$ Serviço que abrange várias escolas e é desenvolvido por um docente especializado que colabora periodicamente com o professor da sala comum que trabalha com alunos com deficiência (BRASIL, 1994).
} 


\subsection{O Atendimento Educacional Especializado em Salas de Recursos MultifunCiOnAIS}

Como já mencionado reiteradas vezes, tem havido em nosso país, nos últimos anos, uma crescente participaçáo do aluno da Educação Especial no sistema regular de ensino e um avanço em sua escolaridade. Isto se deve, em grande parte, às políticas educacionais - em particular, as de Educaçáo Especial - que constituem a inclusão como prioridade. De acordo com o Censo Escolar 2010, no período entre 2007 e 2010, houve um crescimento importante nas matrículas de educação especial na Educação Básica. Em 2007, este número era de 654.606 matrículas, enquanto que em 2010 ampliou-se para 702.603 (BRASIL, 2010a).

Neste mesmo período, ainda é possível observar no Censo Escolar 2010 que, entre 2007 e 2010, houve uma mudança no modelo educacional hegemônico, consubstanciado nas matrículas majoritariamente realizadas em escolas especializadas, para um quadro em que as matrículas em escolas regulares tornam-se predominantes. De uma maneira específica, em 2007, as matrículas nas instituições especializadas somavam 348.470 e, em 2010, diminuíram substancialmente para 218. 271. Em contrapartida, o número de alunos da Educação Especial incluídos em escolas regulares passou de 306.136, em 2007, para 484.332, em 2010.

Este avanço no atendimento e na escolaridade do aluno da Educação Especial também não é diferente na rede de educação de Maceió/AL. De acordo com o índice de evoluçấo de matrículas da SEMED, em 1990, Maceió possuía 83 alunos devidamente matriculados com algum tipo de necessidade educacional especial (MACEIÓ, 2012b). No ano 2000, este número cresceu para 132 alunos, dado que não altera expressivamente o panorama organizacional do sistema escolar. Este acréscimo não pode ser considerado expressivo, pois, de acordo com o Censo Demográfico 2000, 14,5\% da população brasileira, neste período, possuía alguma deficiência, sendo a maior proporção encontrada na regiáo Nordeste, com $16,8 \%$ da população (BRASIL, 2003).

Esta realidade na educação de pessoas com deficiência no sistema municipal de educação de Maceió só veio a se modificar mais significativamente a partir de 2010, quando se presencia o maior índice de alunos matriculados na rede, até a época, com um total de 1.103 alunos (BRASIL, 2011d; MACEIÓ, 2012b). No ano seguinte, este número amplia-se ainda mais e marca 1.546 matrículas de alunos com deficiência, sendo que 100 delas eram na educação infantil, 1.321 no ensino fundamental e 125 na educação de jovens e adultos - nível fundamental (BRASIL, 2011d). De igual forma, a capital alagoana acompanha a tendência para o desenvolvimento educacional observado em nível nacional, conforme indicado nos dados do Censo Escolar 2010 (BRASIL, 2010a).

Todavia, apesar de se vislumbrar uma nova etapa na história da educação das pessoas com deficiências - historicamente excluídas do convívio e da participação social - não se pode afirmar que elas efetivamente estejam incluídas nos espaços educacionais, em virtude das inúmeras barreiras que atravancam o processo de inclusão. De acordo com Hora e Cruz (2008), estas barreiras se apresentam como qualquer forma de entrave ou obstáculo que limite ou impeça uma pessoa de ter acesso livre e irrestrito ao meio educacional, bem como nele progredir.

No intuito de contribuir para a minimização das barreiras que podem gerar um quadro de exclusão educacional e aumentar a qualidade do apoio oferecido e necessário para a 
escolarização de alunos da Educação Especial, foi publicado o decreto no 7.611/2011 (BRASIL, $2011 b)_{2}$ que dispóe sobre o AEE. De acordo com este decreto, tal atendimento é definido, no artigo $2^{\circ}$, como um conjunto de atividades, recursos de acessibilidade e pedagógicos organizados institucional e continuamente, prestado de forma complementar ${ }^{16}$ ou suplementar ${ }^{17}$ à formação dos alunos no ensino regular.

O Decreto em questão, no art. $5^{\circ}$, define que o AEE deverá ser ofertado aos estudantes da rede pública de ensino regular pelos sistemas públicos de ensino ou por instituiçóes comunitárias, confessionais ou filantrópicas sem fins lucrativos.

Dada a importância atribuída ao AEE para a promoção da educação brasileira numa perspectiva inclusiva, buscou-se desvendar como este serviço tem sido implementado nas escolas da rede de ensino do município de Maceió/AL. Constatou-se que o AEE na rede municipal de educação de Maceió tem sido ofertado prioritariamente em SRM, implantadas em unidades escolares da própria rede, e sem convênio ${ }^{18}$ com instituições comunitárias, confessionais ou filantrópicas. A oferta desse serviço teve financiamento único e exclusivo do Ministério da Educação, através dos programas de implantação de SRM e de formação continuada de professores do AEE.

O processo de implantação das SRM na cidade de Maceió/AL é ainda muito recente e está sendo acompanhado pelo DEE/SEMED, que é formado por 1 coordenadora - responsável pelas ações do setor - e 12 técnicos, cuja função é auxiliar no processo de formação continuada dos professores que atuam nas SRM e nas salas de aula comuns, atender e acompanhar a demanda das unidades escolares da rede municipal de Educação Básica em relação ao processo de inclusão, bem como monitorar e planejar as ações do Benefício de Prestação Continuada na Escola. Além disso, o DEE é responsável por analisar o processo de orientação e implantação dos serviços de Atendimento Educacional Especializado.

Para facilitar a visualização do processo de implantação das SRM, o gráfico 1 mostra o número de salas (tipo I e tipo II) implantadas no período de 2005-2012.

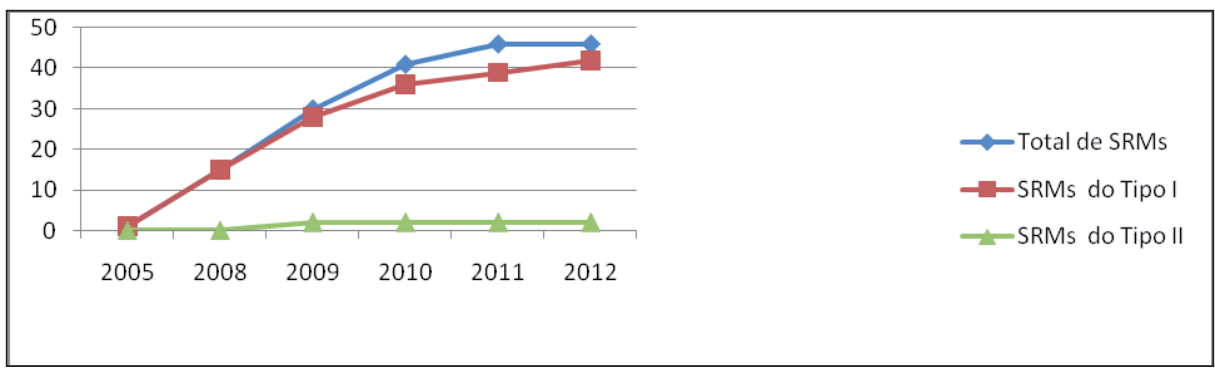

Gráfico 1 - Número de SRM (Tipo I e Tipo II) implantadas em Maceió/AL, de 2005 a 2012

Fonte: Elaboração dos autores a partir dos dados fornecidos pelo Departamento de Educação Especial da SEMED-Maceió/AL

${ }^{16}$ O termo "complementar" refere-se à formação dos alunos com deficiência e com transtornos globais do desenvolvimento (BRASIL, 2011b).

${ }^{17} \mathrm{O}$ termo "suplementar" refere-se à formação de alunos com altas habilidades ou superdotação (BRASIL, 2011b).

${ }^{18}$ Neste ano de 2012, a SEMED recebeu propostas de convênios de algumas instituiçôes filantrópicas, que ainda estão em análise. 
Como se pode observar no gráfico 1, a implantação das Salas de Recursos Multifuncionais na cidade de Maceió/AL teve início no ano de $2005^{19}$, com a inauguração de uma SRM. Nos anos de 2006 e 2007, o município não recebeu nenhum equipamento. Porém, no período de 2008 a 2010, houve um crescimento significativo do número de SRM implantadas, totalizando 41 salas em 41 escolas da rede de ensino. Cabe destacar que, neste mesmo período, apenas 36 SRM estavam em pleno funcionamento, sendo 34 salas do tipo I e 2 do tipo $\mathrm{II}^{20}$. As demais não estavam em funcionamento devido à falta de equipamentos, mobiliários e materiais didáticos pedagógicos próprios das SRM.

Em 2011, a rede de ensino de Maceió possuía 46 SRM, sendo que apenas 41 estavam desenvolvendo o $\mathrm{AEE}^{21}$. A causa do não funcionamento de três delas devia-se a ausência dos recursos constituintes da SRM ou de condiçôes de infraestrutura, como, por exemplo, instalação elétrica e acessibilidade arquitetônica. As outras duas SRM não estavam em funcionamento devido à precariedade de infraestrutura do espaço escolar.

No ano de 2012, o AEE deveria ser oferecido em 46 SRM, todavia apenas 42 delas estavam desenvolvendo suas atividades de forma adequada, em virtude da ausência de espaços educacionais adequados à prática do AEE e, também, da carência de profissionais habilitados ao serviço da educação especial.

Este último problema devia-se a não realização de concurso público destinado ao preenchimento do cargo para a área em questão. $O$ último concurso realizado para o AEE pela rede municipal de educação na capital alagoana foi em 2006 e dele eram provenientes 29 professores que atuavam nas SRM até 2012. Os demais professores não ingressaram à rede por intermédio de um concurso público específico para a área do AEE; eram, em grande parte, provenientes de remanejamentos de outros setores da rede municipal. Mais especificamente, 15 professores integravam o quadro funcional previamente e tinham atuado em instituições especializadas no atendimento de pessoas com deficiência; e os outros 16 professores foram remanejados do sistema regular de ensino, aderindo ao termo de compromisso - documento que estabelece o retorno ao sistema regular de ensino após a contratação dos novos concursados efetivos.

Ainda no que se refere aos professores que lecionavam em 2012, no AEE das SRM da rede municipal de ensino de Maceió/AL, chama a atenção o fato de que todos, sem exceção, tinham a formação mínima exigida para o exercício desta atividade, isto é, formação inicial, que os habilitava ao exercício da docência, e curso de especialização lato sensu nas áreas de Educação Especial e/ou Psicopedagogia (BRASIL, 2009).

Cabe ainda destacar que, no caso dos professores das SRM da rede municipal de Maceió/AL, além da formação em nível de pós-graduação nas áreas já mencionadas, alguns também possuíam especialização em AEE e em Tecnologia Assistiva. Estas duas últimas especializações foram desenvolvidas pelo Ministério da Educação, através do Programa de

\footnotetext{
${ }^{19}$ Ano em que se inicia nacionalmente a implantação do serviço de AEE, através das Salas de Recursos Multifuncionais.

${ }^{20}$ A Sala de Recursos Multifuncionais do tipo II contém todos os materiais da sala do tipo I, acrescidos de recursos de acessibilidade específicos para alunos com deficiência visual.

${ }^{21}$ O Censo Escolar 2011 (BRASIL, 20011d) aponta que 789 alunos do público-alvo da Educação Especial recebiam o AEE, merecendo destaque a grande quantidade de alunos com deficiência intelectual -584 no total.
} 
Formação Continuada de Professores na Educação Especial, na modalidade a distância. A proposta deste Programa é atender às demandas do processo de implantação das SRM, que exige a reestruturação das práticas pedagógicas, contemplando professores que atuam no AEE e nas salas de aula comuns (BRASIL, 2011c).

As açôes de formação continuada devem ser fomentadas, incentivadas e devidamente financiadas pelos órgãos governamentais, confirmando, dessa forma, o que está disposto no Art. $5^{\circ}$ do decreto ${ }^{\circ}$. 7.611, de 17 de novembro de 2011 (BRASIL, 2011b), que diz:

A União prestará apoio técnico e financeiro aos sistemas públicos de ensino, e a instituiçóes comunitárias, confessionais ou filantrópicas, sem fins lucrativos, contribuindo na formação continuada de professores, gestores e demais profissionais da escola para a educação na perspectiva da educação inclusiva.

Além das formações oferecidas pelo MEC, o DEE/SEMED contribuía na formação continuada $^{22}$ dos profissionais das SRM e também na de professores que atuavam em salas de aula comuns da rede municipal de Maceió/AL. Para Lykouropoulos (2007), as formações estavam sendo utilizadas, pelo DEE/SEMED, como os principais instrumentos para a emancipação da inclusão escolar nessa rede de ensino, realizando cursos de especialização, seminários, capacitaçóes ou reunióes periódicas.

A formação continuada deve acontecer para que os professores possam garantir um atendimento educacional qualificado, promovendo a construção de uma educação fundamentada nos preceitos da educação inclusiva, já que é da sua ação mediadora que, muitas das vezes, o aprendizado do aluno depende. No entanto, o professor não pode ser visto como o único responsável por esse processo. Em qualquer nível que ocorra, a inclusão implica profundas mudanças na organização institucional, remodelação do modelo educativo e pedagógico, entre outras, as quais estão muito além das possibilidades de ação do professor.

\section{CONSIDERAÇÓES FINAIS}

Esta pesquisa analisou aspectos históricos e peculiares da Educação Especial em Maceió/AL, o atual processo de implantação da política do atendimento educacional especializado (AEE) na rede municipal desta cidade alagoana e algumas de suas condiçóes geográficas, políticas, econômicas, sociais e educacionais. Os resultados alcançados assinalam que o comprometimento dos gestores municipais com a Educação Especial é recente, embora se observe que as açóes propostas acompanham as discussóes nacionais e internacionais.

Em Maceió, a Educação Especial tem sido gerida pelo DEE/SEMED, que tem contribuído para a formação continuada dos professores da rede, principalmente daqueles que atuam nas SRM. Atualmente, a política educacional estabelecida como prioridade no DEE é a de AEE, que tem sido financiado única e exclusivamente pelo Ministério da Educação.

\footnotetext{
${ }^{22}$ No ano de 2012, a SEMED desenvolveu as seguintes formaçôes: Formação Continuada de Professores do Atendimento Educacional Especializado; Formaçāo Continuada de Professores em Educação Infantil na Perspectiva Inclusiva; e Formação Continuada em Deficiência Visual.
} 
A oferta desse serviço especializado tem sido realizada prioritariamente nas SRM, e não há nenhuma espécie de convênio com instituições comunitárias, confessionais e filantrópicas. A respeito do AEE, pode-se ponderar que as precárias estruturas arquitetônicas dos espaços escolares da rede municipal de ensino e a insuficiência de profissionais habilitados para o exercício da função têm interferido incisivamente na organização e no funcionamento das SRM.

Postas as condições que marcam a Educação Especial no Município de Maceió, conclui-se que estes resultados são congruentes com os problemas de ordem econômica, política, social e educacional vivenciados pela capital alagoana. Diante disso, urge a adoção de políticas/ações que promovam não somente a melhoria da formação profissional especializada para o AEE e das condiçóes de infraestrutura do espaço escolar, mas também o fortalecimento de um sistema municipal de educação que por muito tempo vem sofrendo com o descaso de más administraçôes públicas. Uma vez garantidos esses meios, melhores condiçóes de ensino serão proporcionadas para o aluno da Educação Especial.

\section{REFERÊNCIAS}

ALAGOAS. SEE/AL. Plano Estadual de Educação 2006-2015. Maceió: SEE/AL, 2005.

. Anuário Estatístico do Estado de Alagoas 2010. Maceió: SEPLANDE, 2011.Disponível em: $<$ http://informacao.seplande.al.gov.br/sites/default/files/pdf/anuario_2010_0.pdf>. Acesso em: 05 maio 2013.

Produto Interno Bruto dos Municípios Alagoanos 2008-2009. Maceió: SEPLANDE, 2012. Disponível: <http://informacao.seplande.al.gov.br/pageflips/PIB_mun_2012-2006_2009/ HTML/\#/14/>. Acesso: 18 ago. 2012.

BRASIL. Constituição (1988). Constituição da República Federativa do Brasil. Brasília, DF: Senado, 1988.

. MEC. Política Nacional de Educação Especial. Brasília, DF: MEC/SEESP, 1994.

. MEC. Lei de diretrizes e bases da educação nacional. Brasília, DF: MEC/CNE, 1996.

. IBGE. Censo Demográfico 2000. Rio de Janeiro: IBGE, 2003.

. MEC. Política Nacional de Educação Especial na Perspectiva da Educação Inclusiva. Brasília, DF: MEC, 2008.

. MEC. Resolução nº. 4, de 2 de outubro de 2009. Brasília, DF: MEC, 2009.

. INEP. Censo Escolar 2010: versão preliminar. Brasília, DF: MEC/CNE, 2010a.

. IBGE. IBGE Cidades@ 2010. Brasília, DF: IBGE, 2010b. Disponível em: <http://www.ibge. gov.br/cidadesat/link.php?uf=al>. Acesso em: 05 maio 2013.

. IBGE.IBGE Estados@. Brasília, DF: IBGE, 2010c. Disponível em: <http://www.ibge.gov.br/ estadosat/perfil.php?sigla=al>. Acesso em: 24 ago. 2012.

. INEP. Censo de Educação Superior 2010. Brasília, DF: MEC/CNE, 2010d.

. IBGE. Indicadores Sociais Municipais: uma análise dos resultados do universo do Censo

Demográfico 2010. Rio de Janeiro: IBGE, 2011a. 
. MEC. Decreto no 7.611, de 17 de novembro de 2011. Brasília, DF: MEC, $2011 \mathrm{~b}$.

. Ministério da Educação. Programa de Formação Continuada de Professores na Educação Especial - Modalidade a Distância. Brasília, DF: MEC, 2011c. Disponível em: <http://portal.mec.gov. $\mathrm{br} /$ index.php?option=com_content\&view=article\&id=14188\%3Aprograma-formacao-continuadade-professores-na-educacao-especial-modalidade-distancia\&catid=192\%3Aseesp-esducacao-especial\&Itemid=826>. Acesso em: 29 nov. 2011.

. MEC. Censo Escolar 2011. Brasília, DF: MEC, 2011d.

. MEC. Censo Escolar 2012. Brasília, DF: MEC, 2012a.

. MEC. Sistema e-MEC: Instituições de Educação Superior e Cursos Cadastrados - 2012. Brasília: MEC, 2012b. Disponível em: <http://emec.mec.gov.br/>. Acesso em: 30 ago. 2012.

. MEC/INEP. IDEB - Resultados e Metas. Disponível em: <http://ideb.inep.gov.br/resultado/>. Brasília, DF: INEP, 2012c. Acesso em: 20 ago. 2012.

BARROS, J. L.V. A formação continuada de professores na perspectiva da educação inclusiva no município de Maceió. 2011. 203f. Dissertação (Mestrado em Educação Brasileira), Centro de Educação, Universidade Federal de Alagoas, Maceió, 2011.

CALDAS, D. M. Causas persistentes da desigualdade de renda em Alagoas: análise de decomposição do índice Theil-T. Economia política do desenvolvimento, Maceió, v.3, n.8, p.73-100, 2010.

CAPELLINI,V. L. M. F; RODRIGUES, O. M. P. R. Concepçóes de professores acerca dos fatores que dificultam o processo da Educação Inclusiva. Educação (PUCRS. Impresso), Porto Alegre, v.32, n.3, p.355-364, 2009.

CARVALHO, C. P. Políticas públicas e distribuição de renda: o caso de Alagoas. In: ENCONTRO NACIONAL DE ECONOMIA POLÍTICA, 13., 2008, João Pessoa. Anais eletrônicos... São Paulo: SEP, 2008. Disponível em: <http://www.sep.org.br/artigo/3_congresso/1271_13ea045eaa1da80fd4754 26a122715fe.pdf. Acesso em: 23 mar. 2011.

CHACON, M.C.M. Formação de Recursos Humanos em Educação Especial: resposta das universidades à recomendação da Portaria Ministerial n. ${ }^{0}$ 1.793. Revista Brasileira de Educação Especial, Marília, v.10, n.3, p.321-336, 2004.

DIAS, M. C. Atendimento educacional especializado complementar e a deficiência intelectual: consideraçôes sobre a efetivação do direito à educação. 2010. 156f. Dissertação (Mestrado em Educação) - Programa de Pós-Graduação em Educação, Universidade de São Paulo, São Paulo, 2010.

FLICK, U. Uma introdução à pesquisa qualitativa. 2. ed. Porto Alegre: Bookman, 2009.

HORA, E.; CRUZ, H. S. Acessibilidade e Barreiras: percepção dos alunos com deficiências na Universidade Federal de Sergipe. In: CONGRESSO BRASILEIRO DE EDUCAÇÃO ESPECIAL, 3., 2008, São Carlos. Anais...São Carlos: UFSCar, 2008. 1 CD-ROM.

JANNUZZI, G. S. M. Educação do deficiente no Brasil: dos primórdios ao início do século XXI. Campinas: Autores Associados, 2004.

LINS, R. D. Rede de avaliação e capacitação para a implementação dos planos diretores participativos. Maceió: PDP, 2010. Disponível em: <http://web.observatoriodasmetropoles.net/planosdiretores/ produtos/relatorioestadualalagoas.pdf. Acesso em: 02 maio 2013. 
LYKOUROPOULOS, C.B. Inclusão escolar de alunos com deficiência: um estudo das propostas e açóes políticas e sua apropriação das escolas. 2007. 143f. Dissertação (Mestrado em Educação) - Pontifícia Universidade Católica, São Paulo, 2007.

MACEIÓ. SEMED. Plano Municipal de Educação 2011-2021. Maceió: SEMED, 2012a. . SEMED. Evolução de Matrículas por Modalidade de 1990 a 2011. Maceió: SEMED, 2012b. . SEMED. Evolução das SRM Tipo I e Tipo II de 2005-2012. Maceió: SEMED, 2012c.

MELO, S.T.; LINS, R.D.B. O fenômeno dos assentamentos humanos precários em áreas urbanas ambientalmente frágeis: o caso das favelas do Dique-Estrada em Maceió/Alagoas. In: ENCONTRO NACIONAL DA ASSOCIAÇĀO NACIONAL DE PÓS-GRADUAÇÃO E PESQUISA EM AMBIENTE E SOCIEDADE, 5., 2010, Florianópolis. Anais eletrônicos... Florianópolis: EANPPAS, 2010. Disponível em: <http://www.anppas.org.br/encontro5/cd/artigos/GT3-848-99120100903191215.pdf>. Acesso em: 16 abr. 2014.

MENDES, E. G. Breve histórico da Educação Especial no Brasil. Revista Educación y Pedagogía, Medellín, v. 22, n. 57, p. 93-109, 2010.

MILANESE, J. B. A organização e o funcionamento das salas de recursos multifuncionais em um município paulista. 2012. 183f. Dissertação (Mestrado em Educação Especial) - Programa de PósGraduação em Educaçáo Especial, Universidade Federal de Sáo Carlos, São Carlos, 2012.

MONTEIRO, A. P. H. MANZINI, E. J. Mudanças nas concepçóes do professor do ensino fundamental em relação à inclusão após a entrada de alunos com deficiência em sua classe. Revista Brasileira de Educação Especial, Marília, v.14, n.1, p.35-52, 2008.

SANTOS, S.D.G. Autoconfrontação e o processo de inclusão: (re) vendo a atividade docente na educação superior. 2011. 120f. Dissertação (Mestrado em Educação Brasileira) - Centro de Educação, Universidade Federal de Alagoas, Maceió, 2011.

SILVA, J. D. N. Urbanização e saúde em Maceió, AL: o caso dos bairros Vergel do Lago, Jacintinho e Benedito Bentes. 2011. 132f. Dissertaçáo (Mestrado em Dinâmicas do Espaço Habitado) - Faculdade de Arquitetura e Urbanismo, Universidade Federal de Alagoas, Maceió, 2011.

SUICA, G. Z. L. Crimes de homicídios no município de Maceió-AL tratados através do geoprocessamento. Revista Geonorte, Manaus, v.2, n.4, p.1406 -1414, 2012.

WAISELFISZ, J. J. Mapa da violência 2012: Novos padrôes de homicida no Brasil. São Paulo: Instituto Sangari, 2012.

Recebido em: 25/07/2013

Reformulado em: 06/05/2014

Aprovado em: 10/05/2014 